\title{
Are Retinal Arteriolar or Venular Diameters Associated with Markers for Cardiovascular Disorders? The Rotterdam Study
}

\author{
M. Kamran Ikram, ${ }^{1}$ Frank Jan de Jong, ${ }^{1}$ Jobannes $R$. Vingerling, ${ }^{1,2}$ \\ Jacqueline C. M. Witteman, ${ }^{1}$ Albert Hofman, ${ }^{1}$ Monique M. B. Breteler, ${ }^{1}$ and \\ Paulus T. V. M. de Jong ${ }^{1,3,4}$
}

PuRPose. A lower retinal arteriolar-to-venular ratio (AVR) has been suggested to reflect generalized arteriolar narrowing and to predict the risk of cardiovascular diseases. The contribution of the separate arteriolar and venular diameters to this AVR is unknown. Thus, associations between retinal arteriolar and venular diameters, and the AVR on the one hand and blood pressure, atherosclerosis, inflammation markers, and cholesterol levels on the other were examined in the Rotterdam Study.

MethoDs. In this cross-sectional population-based study, for one eye of each subject ( $\geq 55$ years; $n=5674$ ), retinal arteriolar and venular diameters (in micrometers) of the blood columns were summed on digitized images. At baseline blood pressures, cholesterol levels, and markers of atherosclerosis and inflammation were also measured.

Results. With increasing blood and pulse pressures, retinal arteriolar and venular diameters and the AVR decreased significantly and linearly. Lower arteriolar diameters were associated with increased carotid intima-media thickness. Larger venular diameters were associated with higher carotid plaque score, more aortic calcifications, lower ankle-arm index, higher leukocyte count, higher erythrocyte sedimentation rate, higher total serum cholesterol, lower HDL, higher waist-to-hip ratio, and smoking. A lower AVR was related to increased carotid intima-media thickness, higher carotid plaque score, higher leukocyte count, lower HDL, higher body mass index, higher waist-to-hip ratio, and smoking.

Conclusions. Because larger venular diameters are associated with atherosclerosis, inflammation, and cholesterol levels, the AVR does not depend only on generalized arteriolar narrowing

From the Departments of ${ }^{1}$ Epidemiology and Biostatistics and ${ }^{2}$ Ophthalmology, Erasmus Medical Center, Rotterdam, The Netherlands; ${ }^{3}$ The Netherlands Ophthalmic Research Institute, KNAW, Amsterdam, The Netherlands; and the ${ }^{4}$ Department of Ophthalmology, Academic Medical Center, Amsterdam, The Netherlands.

Supported by the Netherlands Organization for Scientific Research (NWO; Grant 904-61-155), The Hague; Optimix Foundation, Amsterdam; The Netherlands Society for the Prevention of Blindness, Doorn; Blindenpenning Foundation, Amsterdam; Fondsenwerving Volksgezondheid Foundation, The Hague; Topcon Europe BV, Capelle aan de IJssel; ROOS Foundation, Rotterdam; Stichting Alzheimer Nederland; and the Edward and Marianne Blaauw Foundation, Amsterdam.

Submitted for publication December 23, 2003; revised February 9, 2004; accepted February 24, 2004.

Disclosure: M.K. Ikram, None; F.J. de Jong, None; J.R. Vingerling, None; J.C.M. Witteman, None; A. Hofman, None; M.M.B. Breteler, None; P.T.V.M. de Jong, None

The publication costs of this article were defrayed in part by page charge payment. This article must therefore be marked "advertisement" in accordance with 18 U.S.C. $\$ 1734$ solely to indicate this fact

Corresponding author: Paulus T.V.M. de Jong, The Netherlands Ophthalmic Research Institute, KNAW, Meibergdreef 47, 1105 BA Amsterdam, The Netherlands; p.dejong@ioi.knaw.nl. due to the association between smaller arteriolar diameters and higher blood pressures. These data indicate that retinal venular diameters are variable and may play their own independent role in predicting cardiovascular disorders. (Invest Ophthalmol Vis Sci. 2004;45:2129-2134) DOI:10.1167/iovs.03-1390

S tructural changes in the retinal vasculature have long been $\checkmark$ recognized as an important predictor of systemic hypertensive damage and life prognosis. ${ }^{1,2}$ Different classifications mainly depended on qualitative assessment of retinal vessels using ophthalmoscopy, which has a poor reproducibility and gauges arteriolar diameters against the venular ones. ${ }^{3}$

Recently, in the Atherosclerosis Risk in Communities (ARIC) Study, a semiautomated system was developed to measure the vessel diameters on fundus photographs. ${ }^{4-6}$ The authors attributed a lower arteriolar-to-venular ratio (AVR) to generalized arteriolar narrowing and suggested that this ratio may provide information that would predict incident cardiovascular diseases independently of known cardiovascular risk factors. ${ }^{6-14}$ Compared with other retinal signs such as hemorrhages, focal arteriolar narrowing, and arteriovenous nicking, the AVR was the more reliable and commonly used parameter of vascular damage. ${ }^{6,8-11,15}$

It remains unclear, however, what exactly the separate arteriolar and venular diameters contributed to the AVR and what kind of vascular disease this ratio precisely reflects. Limited data have been published on the association between AVR or retinal vessel diameters and blood pressure. ${ }^{6,11-13}$ Associations concerning AVR and atherosclerosis were inconclusive. ${ }^{15,16}$ Currently, no data are available on the specific relationship between arteriolar or venular diameters and atherosclerosis, inflammation markers, or cholesterol levels. We therefore investigated these cross-sectional associations in a population-based setting.

\section{Materials ANd Methods}

\section{Population}

The present study was performed as part of the Rotterdam Study, a population-based, cohort study on chronic and disabling diseases in the elderly. A total of 7983 subjects 55 years of age and older living in a district of Rotterdam agreed to participate in the study. Information on the baseline study population has appeared in previous reports. ${ }^{17,18}$ Because the ophthalmic part became operational after the screening of participants had started, a smaller number $(n=6780)$ participated in the ophthalmic examination. ${ }^{19}$ The study was conducted according to the tenets of the Declaration of Helsinki, and the Medical Ethics Committee of the Erasmus Medical Center approved the study protocol. A written informed consent was obtained from all participants. Baseline interviews and examinations were performed from 1990 to mid-1993. 


\section{Retinal Vessel Measurements}

After the eye examination at baseline, simultaneous stereoscopic fundus color transparencies centered on the optic disc (pharmacological mydriasis, $20^{\circ}$; Topcon Optical Co., Tokyo, Japan) were digitized with a high-resolution scanner (model LS-4000; Nikon Corp., Tokyo, Japan). ${ }^{18}$ For each subject, the image with the best quality (left or right eye) was analyzed with a semiautomated system (Retinal Analysis; Optimate, Madison, WI; Department of Ophthalmology and Visual Science, University of Wisconsin-Madison) by four trained graders masked to the end points. ${ }^{4-6}$ We used the improved Parr-Hubbard formula to compute the summary vessel measures. ${ }^{20}$ Because each eye has a different magnification due to its optical system (lens, cornea) we additionally adjusted this summary vessel measure for the refraction and corneal curvature using Littmann's formula to obtain absolute measures. ${ }^{21}$ On one eye of each subject one sum value was calculated for the arteriolar blood column diameter and one for the venular (in micrometers), the AVR being the ratio of these. In a random subsample of 100 subjects we found no differences between the right and left eyes for the arteriolar and venular diameters.

Quality control sessions with a random subsample of 40 transparencies gave the following Pearson's correlation coefficients for intergrader agreement 0.67-0.80 (arteriolar diameter), 0.91-0.94 (venular diameter), and 0.75-0.84 (AVR). For intragrader agreement these were $0.69-0.88,0.90-0.95$, and $0.72-0.90$, respectively.

\section{Blood Pressure, Atherosclerosis, Inflammation, and Cholesterol}

Blood pressures, ankle-arm index, intima-media thickness, carotid artery plaques, and aortic atherosclerosis were measured as described previously. ${ }^{22-24}$

Briefly, intima-media thickness of the common carotid artery was assessed by ultrasonography, using a $7.5-\mathrm{MHz}$ linear-array transducer (ATL Ultra-Mark IV; Advanced Technology Laboratories, Bethel, Western Australia). For the current analyses, the average of the mean anterior and posterior intima-media thickness of both the left and the right common carotid artery was used. Atherosclerotic plaques, assessed by ultrasound at the bifurcation, common, and internal carotid artery on both sides, were defined as focal thickening of the vessel wall (of at least 1.5 times the average intima-media thickness) relative to adjacent segments, with or without calcified components. The carotid plaque score (range: $0-6$ ) reflects the number of these locations with plaques. Aortic atherosclerosis, defined as calcified deposits in the abdominal aorta on lateral radiographic films of the lumbar spine, was considered present when linear densities were seen in an area parallel and anterior to the lumbar spine (L1-L4). The extent of calcification was scored according to the length of the involved area $(0,0.5$ to $<1$, 1 to $<2.5,2.5$ to $<5,5$ to $<10$, and $\geq 10 \mathrm{~cm}$ ). All readers and technicians were masked to all clinical information.

Leukocyte count was assessed in citrate plasma using a Coulter Counter T540 (Coulter Electronics, Luton, UK). Blood was drawn directly into tubes (Vacutainer; BD Biosciences, Heidelberg, Germany) and erythrocyte sedimentation rate was read after 60 minutes. Nonfasting serum total cholesterol and high-density lipoprotein (HDL) concentrations were determined by an automated enzymatic procedure. ${ }^{25}$ Information on smoking (categorized as current, former, or never) and medication use was obtained during the home interview. Alcohol consumption was assessed as part of a dietary interview. ${ }^{26}$

\section{Study Sample}

Of the 6780 participants in the ophthalmic part, 6436 persons underwent optic disc photography. From these 762 subjects were excluded because they had ungradable fundus transparencies on both eyes, resulting in a cohort of 5674 subjects. Measurements on blood pressure were missing in 91 participants, ankle-arm index in 547, intimamedia thickness in 918, carotid plaque score in 970, aortic calcifications in 1510 , leukocyte count in 394 , erythrocyte sedimentation rate in 1543 , total cholesterol in 44 , HDL cholesterol in 53 , body mass index in 72 , waist-to-hip ratio in 350 , smoking in 65 , and alcohol consumption in 884 . Restricted availability of technicians was the main reason for missing data, which was independent of any subject characteristics.

\section{Statistical Analysis}

Analysis of covariance (ANCOVA) was used to compare subjects with gradable and ungradable transparencies and to analyze whether associations were linear. If so, multiple linear regression models were used to assess these cross-sectional relationships. We analyzed blood pressures both per standard deviation and per 10-mm $\mathrm{Hg}$ increase. The former was taken to compare the effect size between systolic and diastolic blood pressures, and the latter to compare our results with those of other studies.

All analyses were repeated after stratifying on subjects with diseases known to affect venular width such as diabetes mellitus and hypertension. All analyses were performed using SPSS (Windows ver. 11.0; SPSS Inc., Chicago, IL).

\section{Results}

Table 1 shows the baseline characteristics of subjects with gradable and ungradable transparencies. The means were: arteriolar diameter, $146.9 \mu \mathrm{m}$ (range, 92.2-235.7; SD, 14.4), venular diameter, 222.0 $\mu \mathrm{m}$ (range, 135.1-313.6; SD, 20.9), and AVR, 0.66 (range, 0.48 to $1.02 ; \mathrm{SD}, 0.06$ ).

\section{Blood Pressures and Retinal Vessel Diameters}

With increasing blood and pulse pressures, the arteriolar diameters decreased linearly (Table 2). Figure 1 shows that the relationship with the arteriolar diameters was strongest in the youngest age category (per standard deviation increase in systolic blood pressure, $-3.8 \mu \mathrm{m} ; 95 \% \mathrm{CI},-4.7$ to -2.8 ) and became nonsignificant above age 80 years. With increasing blood and pulse pressures, the venular diameters showed a small decrease; when stratified by age, there seemed to be no clear trend.

With increasing blood and pulse pressures, the AVR decreased linearly (Table 2). The relationship with AVR was strongest in the age category 55 to 60 years (Fig. 1). Per standard deviation increase in systolic blood pressure, AVR decreased by 0.016 (95\% CI, 0.012-0.019). Diastolic blood pressure showed the same trends; hence, only systolic blood pressure is presented in Figure 1.

\section{Atherosclerosis and Retinal Vessel Diameters}

The arteriolar diameters did not show an association with the different markers of atherosclerosis except intima-media thickness. After additional adjustment for blood pressure, this association became weaker (per standard deviation increase, -0.6 $\mu \mathrm{m}$; $95 \% \mathrm{CI},-1.0$ to -0.1$)$.

The venular diameters were linearly related to several markers of atherosclerosis. Larger venular diameters were associated with a lower ankle-arm index, higher carotid plaque score, more aortic calcifications (borderline), and a nonsignificantly increased intima-media thickness. Additional adjustment for blood pressure did not alter these associations. Stratification on age did not show a trend between atherosclerosis and retinal venular diameters.

A lower AVR was significantly related to a lower ankle-arm index, increased intima-media thickness, and higher carotid plaque score, but not to aortic calcifications (Table 2). After additional adjustment for blood pressure, AVR was still associated with intima-media thickness (per standard deviation increase, $-0.002 ; 95 \% \mathrm{CI},-0.004$ to -0.001$)$ and carotid plaque 
TABLe 1. Baseline Characteristics

\begin{tabular}{|c|c|c|c|}
\hline & Gradable* $^{*}$ & Ungradable & $\begin{array}{c}\text { Adjusted Differences } † \\
(95 \% \mathrm{CI})\end{array}$ \\
\hline Subjects $(n)$ & 5674 & 762 & \\
\hline Age (y) & $68.0(8.20)$ & $75.7(10.10)$ & $7.8(7.10$ to 8.40$) \S$ \\
\hline Gender (\% female) & 59.0 & 63.0 & $0.1(-3.80$ to 4.00$)$ \\
\hline Institutionalized (\%) & 3.6 & 22.0 & $9.9(8.30$ to 11.60$) 8$ \\
\hline Diabetes mellitus (\%) & 10.0 & 14.0 & $0.9(-1.40$ to 3.30$)$ \\
\hline Systolic blood pressure (mm Hg) & $138.5(22.10)$ & $145.2(24.00)$ & $1.5(-0.20$ to 3.30$)$ \\
\hline Diastolic blood pressure ( $\mathrm{mm} \mathrm{Hg}$ ) & $73.7(11.40)$ & $74.2(12.80)$ & $1.4(0.50$ to 2.30$) \delta$ \\
\hline Pulse pressure (mm Hg) & $64.8(17.70)$ & $71.0(19.70)$ & $0.1(-1.20$ to 1.40$)$ \\
\hline Ankle-arm index & $1.07(0.22)$ & $0.97(0.28)$ & $-0.03(-0.05$ to -0.02$) \S$ \\
\hline Carotid intima-media thickness (mm) & $0.79(0.15)$ & $0.86(0.19)$ & $0.02(0.01$ to 0.03$) \S$ \\
\hline Aorta calcification $\geq 5 \mathrm{~cm} \mathrm{( \% )}$ & 11.1 & 17.6 & $2.1(-1.20$ to 5.40$)$ \\
\hline Carotid plaques $\geq 4(\%)$ & 16.1 & 24.0 & $1.5(-1.70$ to 4.70$)$ \\
\hline Leukocyte count $\left(10^{\circ} / \mathrm{L}\right)$ & $6.7(1.90)$ & $6.8(3.00)$ & $0.1(-0.10$ to 0.20$)$ \\
\hline Erythrocyte sedimentation rate & $12.9(10.70)$ & $16.2(14.40)$ & $1.3(0.20$ to 2.30$) \Phi$ \\
\hline Total serum cholesterol (mmol/L) & $6.63(1.21)$ & $6.53(1.30)$ & $0.01(-0.10$ to 0.10$)$ \\
\hline Serum HDL cholesterol (mmol/L) & $1.35(0.36)$ & $1.34(0.36)$ & $0.00(-0.02$ to 0.03$)$ \\
\hline Body mass index $\left(\mathrm{kg} / \mathrm{m}^{2}\right)$ & $26.3(3.68)$ & $26.0(3.69)$ & $-0.44(-0.73$ to -0.14$) \Phi$ \\
\hline Waist-to-hip ratio & $0.90(0.09)$ & $0.91(0.09)$ & $0.00(-0.01$ to 0.01$)$ \\
\hline \multicolumn{4}{|l|}{ Smoking (\%) } \\
\hline Current & 23.6 & 18.7 & $0.4(-2.90$ to 3.70$)$ \\
\hline Former & 42.9 & 36.8 & $-3.7(-7.40$ to 1.90$)$ \\
\hline \multicolumn{4}{|l|}{ Alcohol consumption (\%) } \\
\hline$\leq 10 \mathrm{~g} / \mathrm{d} \neq$ & 45.0 & 41.9 & $-3.3(-8.10$ to 1.50$)$ \\
\hline$>10-\leq 20 \mathrm{~g} / \mathrm{d}$ & 15.4 & 13.0 & $-1.3(-4.80$ to 2.20$)$ \\
\hline$>20 \mathrm{~g} / \mathrm{d}$ & 19.5 & 19.3 & $1.0(-2.70$ to 4.70$)$ \\
\hline
\end{tabular}

Data are presented as unadjusted means (SD) or percentages.

* Subjects with a gradable fundus transparency on at least one eye.

† Age and gender adjusted if applicable.

$\neq 10$ grams is on average equal to 1 drink.

\& Significant $(P<0.05)$.

score (per plaque increase, $-0.002 ; 95 \% \mathrm{CI},-0.003$ to $-0.001)$.

\section{Inflammation Markers, Cholesterol Levels, and Retinal Vessel Diameters}

Higher leukocyte count, higher erythrocyte sedimentation rate, lower serum HDL levels, higher total serum cholesterol, higher waist-to-hip ratio, and smoking were related to larger venular diameters and to a lesser extent to larger arteriolar diameters, thus resulting in a lower AVR (Table 3).

These analyses were repeated using models in which the cardiovascular variables were categorized. Because all relationships were linear in these analyses, only the linear models are presented. Stratification on subjects with and without hyper-

TABLE 2. Age- and Gender-Adjusted Difference in Retinal Vessel Diameters with Increasing Blood Pressure Levels both per SD and per 10-mm $\mathrm{Hg}$ and with Increasing Severity of Subclinical Atherosclerosis

\begin{tabular}{|c|c|c|c|c|}
\hline & $\boldsymbol{n}$ & $\begin{array}{c}\text { Arteriolar Diameter } \\
(\mu \mathrm{m})\end{array}$ & $\begin{array}{l}\text { Venular Diameter } \\
\qquad(\mu \mathrm{m})\end{array}$ & $\begin{array}{c}\text { Arteriolar-to-Venular } \\
\text { Ratio }\end{array}$ \\
\hline \multicolumn{5}{|l|}{ Blood pressure } \\
\hline $\begin{array}{l}\text { Per SD increase } \\
\text { Per } 10-\mathrm{mm} \mathrm{Hg} \text { increase }\end{array}$ & 5583 & $\begin{array}{l}-2.4(-2.8 \text { to }-2.0)^{*} \\
-1.1(-1.3 \text { to }-0.9)^{*}\end{array}$ & $\begin{array}{l}-1.0(-1.6 \text { to }-0.5)^{*} \\
-0.5(-0.7 \text { to }-0.2)^{*}\end{array}$ & $\begin{array}{l}-0.008(-0.009 \text { to }-0.006)^{*} \\
-0.0035(-0.004 \text { to }-0.003)^{*}\end{array}$ \\
\hline \multicolumn{5}{|l|}{ Diastolic Blood Pressure: } \\
\hline $\begin{array}{l}\text { Per SD increase } \\
\text { Per } 10-\mathrm{mm} \mathrm{Hg} \text { increase }\end{array}$ & 5583 & $\begin{array}{l}-2.4(-2.8 \text { to }-2.1)^{*} \\
-2.1(-2.5 \text { to }-1.8)^{*}\end{array}$ & $\begin{array}{l}-0.8(-1.3 \text { to }-0.2)^{*} \\
-0.7(-1.1 \text { to }-0.2)^{*}\end{array}$ & $\begin{array}{l}-0.009(-0.010 \text { to }-0.007)^{*} \\
-0.008(-0.009 \text { to }-0.006)^{*}\end{array}$ \\
\hline \multicolumn{5}{|l|}{ Pulse Pressure: } \\
\hline $\begin{array}{l}\text { Per SD increase } \\
\text { Per } 10-\mathrm{mm} \mathrm{Hg} \text { increase }\end{array}$ & 5583 & $\begin{array}{l}-1.5(-1.9 \text { to }-1.1)^{*} \\
-0.8(-1.1 \text { to }-0.6)^{*}\end{array}$ & $\begin{array}{l}-0.8(-1.4 \text { to }-0.3)^{*} \\
-0.5(-0.8 \text { to }-0.1)^{*}\end{array}$ & $\begin{array}{l}-0.004(-0.006 \text { to }-0.003)^{*} \\
-0.002(-0.003 \text { to }-0.001)^{*}\end{array}$ \\
\hline \multicolumn{5}{|c|}{ Markers of sub-clinical atherosclerosis } \\
\hline $\begin{array}{l}\text { Per SD increase } \\
\text { Carotid plaque-score }\end{array}$ & 4756 & $-0.9(-1.4 \text { to }-0.5)^{*}$ & $-0.2(-0.8$ to 0.5$)$ & $-0.004(-0.005 \text { to }-0.002)^{*}$ \\
\hline $\begin{array}{l}\text { Per plaque increase } \\
\text { Ankle-arm index }\end{array}$ & 4704 & $-0.2(-0.5$ to 0.1$)$ & $0.4(0.1 \text { to } 0.8)^{*}$ & $-0.002(-0.003 \text { to }-0.001)^{*}$ \\
\hline $\begin{array}{l}\text { Per SD decrease } \\
\text { Aorta calcification }\end{array}$ & 5127 & $0.4(0.0$ to 0.8$)$ & $1.3(0.7 \text { to } 1.9)^{*}$ & $-0.002(-0.0004 \text { to }-0.004)^{*}$ \\
\hline Per category increase & 4164 & $0.03(-0.3$ to 0.4$)$ & $0.4(-0.1$ to 0.8$)$ & $-0.001(-0.002$ to 0.001$)$ \\
\hline
\end{tabular}

95\% CI is in parentheses.

* Significant $(P<0.05)$ 
Subjects (n) $10501282 \quad 1141 \quad 950 \quad 657 \quad 339 \quad 124$
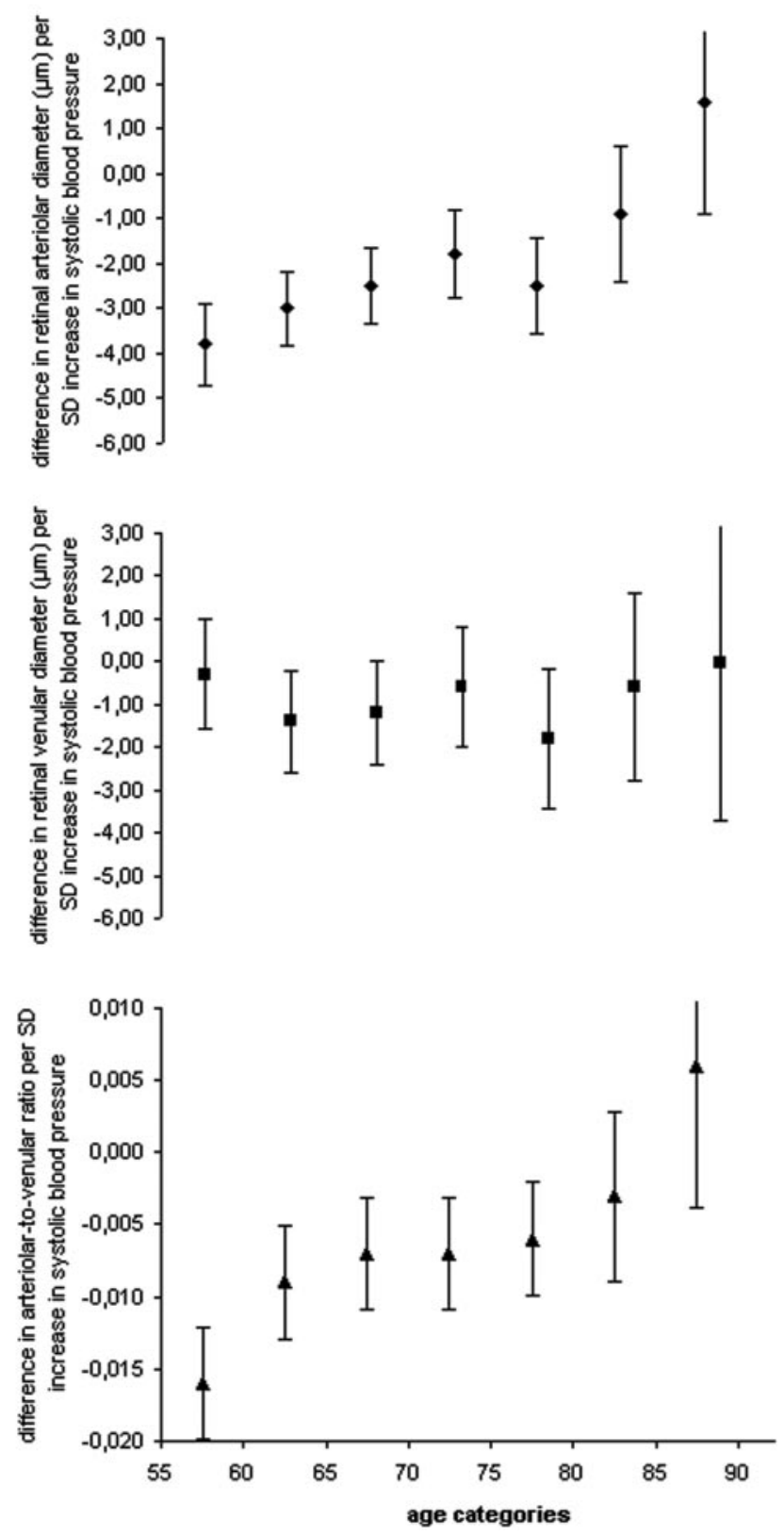

FIGURE 1. The relationship between blood pressure and retinal vessel measurements per 5-year age categories. Age category 90-95 years was excluded because of the low number of subjects $(n=40)$.

tension did not significantly alter any of the above-mentioned results. The results were again the same after stratification according to the presence of diabetes mellitus. However, in subjects with diabetes mellitus the point estimates for these relationships were less stable with wider confidence intervals because only $10 \%$ of the population had diabetes mellitus at baseline.

\section{Discussion}

These results show that higher blood and pulse pressures were related to lower arteriolar diameters. More severe atherosclerosis, as measured by the ankle-arm index, aortic calcifications and carotid plaque score, higher leukocyte count, higher eryth- rocyte sedimentation rate, higher total cholesterol, lower HDL levels, higher waist-to-hip ratio, or smoking were related to larger venular diameters, with the overall effect being a lower AVR.

For proper interpretation some methodological issues warrant consideration. The excluded subjects were on average older and more often institutionalized. This group probably contained more subjects with physical or mental disabilities or lens opacities that contributed to the poor quality of the transparencies. However, there were only small differences in cardiovascular risk factors between the two groups, suggesting a limited role for selection bias.

The cross-sectional setting prevented inferring causality or a chronological order of events. Photographs were not taken synchronized on the cardiac cycle, and thus there may be variation in vessel diameter due to pulsatility. A variation of $2 \%$ to $17 \%$ in vessel diameter has been described. ${ }^{27}$ However, because photography was independent of any subject characteristics, this variation will have caused random misclassification.

Strengths of this study include its population-based design, data collection within a short time span, and the detailed measurement of vessel diameters on $20^{\circ}$ stereoscopic fundus transparencies (leading to higher magnification) obtained after pharmacological mydriasis. Both the ARIC and the Cardiovascular Health studies (CHS) used $45^{\circ}$ photographs without pharmacological mydriasis, whereas the Blue Mountains Eye Study used $30^{\circ}$ photographs through dilated pupils. ${ }^{6,15,13}$ Furthermore, ours seems to be the first study that used the improved Parr-Hubbard formulas and Littmann's correction to approximate absolute intraluminal diameters. ${ }^{20,21}$

\section{Blood Pressure and Retinal Vessel Diameters}

When analyzed separately, the impact of blood pressure was more prominent in younger subjects and more in arterioles than venules, as expected. The decrease in arteriolar diameters not only reflects vasoconstriction but also intimal thickening, medial hyperplasia, hyalinization, and sclerosis. ${ }^{28,29}$ We found smaller decrease in arteriolar diameter (1.1 and $2.1 \mu \mathrm{m}$ per $10-\mathrm{mm} \mathrm{Hg}$ increase in systolic and diastolic blood pressure, respectively) than reported $(1.9$ and $4.3 \mu \mathrm{m}) .{ }^{13}$ Apart from the mentioned differences in grading and measuring techniques, this smaller decrease could be explained by the older age distribution of our cohort (55-99 years) versus that in the ARIC Study ( $48-76$ years) and the Blue Mountains Study (49+ years, only $8 \%$ above age 80 years). ${ }^{6,13}$ In the older age groups, the vessels become progressively rigid and lose their ability to react adequately to blood pressure changes. ${ }^{30,31}$

The association between venular diameter and blood pressure was weak, and, when stratified by age, there was no trend. In our oldest age category, the estimate may be unstable due to the low number of subjects.

\section{Atherosclerosis and Retinal Vessel Diameters}

There was no relationship between the arteriolar diameters and markers of atherosclerosis, except for intima-media thickness. Apart from being a marker of atherosclerosis, intimamedia thickness may indicate a response of the artery wall to changes in shear and tensile stress due to hypertension. ${ }^{32}$ This is also supported by our data, because after additional adjustment for blood pressure this association became weaker.

We did find a relationship between atherosclerosis and larger venular diameters. A clear pathophysiological explanation for this association is lacking. It is known that in diabetic retinopathy, the retinal venules become wider. ${ }^{33}$ Other examples of venular dilatation are patients with central retinal vein occlusion, carotid artery narrowing leading to so-called venous 
Table 3. Age- and Gender-Adjusted Difference in Retinal Vessel Diameters with Increasing Levels of Inflammation, Cholesterol, Smoking and Alcohol Consumption

\begin{tabular}{|c|c|c|c|c|}
\hline & $n$ & $\begin{array}{l}\text { Arteriolar Diameter } \\
\qquad(\mu \mathrm{m})\end{array}$ & $\begin{array}{l}\text { Venular Diameter } \\
\qquad(\mu \mathrm{m})\end{array}$ & Arteriolar-to-Venular Ratio \\
\hline Leukocyte count: per SD increase & 5280 & $1.1(0.8 \text { to } 1.5)^{*}$ & $2.9(2.4 \text { to } 3.5)^{*}$ & $-0.003(-0.005 \text { to }-0.002)^{*}$ \\
\hline Erythrocyte sedimentation rate: per SD increase & 4131 & $0.7(0.3 \text { to } 1.2)^{*}$ & $0.8(0.1 \text { to } 1.5)^{*}$ & $0.001(-0.001$ to 0.003$)$ \\
\hline Total serum cholesterol: per SD increase & 5630 & $0.2(-0.2$ to 0.6$)$ & $0.4(-0.1$ to 1.0$)$ & $-0.0002(-0.002$ to 0.001$)$ \\
\hline Serum HDL cholesterol: per SD increase & 5621 & $-0.5(-0.9 \text { to }-0.1)^{*}$ & $-1.2(-1.8 \text { to }-0.7)^{*}$ & $0.001(0.000 \text { to } 0.003)^{*}$ \\
\hline Body mass index: per SD increase & 5602 & $-0.7(-1.1 \text { to }-0.3)^{*}$ & $0.1(-0.4$ to 0.7$)$ & $-0.004(-0.005 \text { to }-0.002)^{*}$ \\
\hline Waist-to-hip ratio: per SD increase & 5324 & $-0.2(-0.6$ to 0.3$)$ & $1.1(0.4 \text { to } 1.7)^{*}$ & $-0.004(-0.006 \text { to }-0.002)^{*}$ \\
\hline \multicolumn{5}{|l|}{ Smoking: } \\
\hline $\begin{array}{l}\text { Current vs. nonsmokers } \\
(n=1324 \text { vs. } n=1877)\end{array}$ & & $5.0(3.9 \text { to } 6.0)^{*}$ & $10.0(8.3 \text { to } 11.4)^{*}$ & $-0.007(-0.011 \text { to }-0.003)^{*}$ \\
\hline $\begin{array}{l}\text { Former vs. nonsmokers } \\
(n=2408 \text { vs. } n=1877)\end{array}$ & & $1.3(0.4 \text { to } 2.3)^{*}$ & $2.5(1.2 \text { to } 3.9)^{*}$ & $-0.002(-0.006$ to 0.002$)$ \\
\hline \multicolumn{5}{|l|}{ Alcohol consumption: } \\
\hline $\begin{array}{l}\leq 10 \mathrm{~g} / \mathrm{d} \text { vs. nondrinkers } \\
(n=2158 \text { vs. } n=965)\end{array}$ & & $0.6(-0.5$ to 1.7$)$ & $0.6(-0.9$ to 2.2$)$ & $0.001(-0.004$ to 0.005$)$ \\
\hline $\begin{array}{l}>10 \text { to } \leq 20 \mathrm{~g} / \mathrm{d} \text { vs. nondrinkers } \\
(n=737 \text { vs. } n=965)\end{array}$ & & $-1.0(-2.4$ to 0.4$)$ & $-0.9(-2.9$ to 1.1$)$ & $-0.002(-0.008$ to 0.003$)$ \\
\hline $\begin{array}{l}>20 \mathrm{~g} / \mathrm{d} \text { vs. nondrinkers } \\
(n=930 \text { vs. } n=965)\end{array}$ & & $-1.1(-2.4$ to 0.3$)$ & $1.5(-0.4$ to 3.4$)$ & $-0.010(-0.015 \text { to }-0.004)^{*}$ \\
\hline
\end{tabular}

95\% CI is in parentheses.

* Significant $(P<0.05)$.

stasis retinopathy, or deep venous thrombosis in the legs, who also have more often atherosclerosis. ${ }^{34,35}$ It has been suggested that hyperlipidemia, platelet activation, and blood coagulation are involved in the development of both atherosclerosis and venous thrombosis. ${ }^{35}$ Whether atherosclerosis induces venular changes, both share common risk factors, or they occur independently of each other still has to be elucidated.

In the CHS study, atherosclerosis, as measured by anklearm index, carotid plaques, and intima-media thickness was, contrary to our findings, not related to AVR. ${ }^{15}$ Selection bias may have occurred, because they performed carotid ultrasonography 5 years before fundus photography. ${ }^{15}$ In the ARIC study, however, a lower AVR was related to more carotid plaques, ${ }^{16}$ and in our study the relationship with AVR persisted for intima-media thickness and carotid plaque score after adjusting for blood pressures. The relationship between markers of atherosclerosis and AVR is mainly driven by larger venular diameters.

\section{Inflammation Markers, Cholesterol Levels, and Retinal Vessel Diameters}

Higher leukocyte count, higher erythrocyte sedimentation rate, lower HDL levels, higher waist-to-hip ratio, and smoking were associated with larger arteriolar and even more strongly with larger venular diameters. Because inflammation also plays an important part in atherosclerosis, vessel widening in these conditions may be due to similar mechanisms. We hypothesize that disruption of the endothelial surface layer (ESL) may underlie the apparent vessel widening. The endothelial surface of all vessels is coated with a matrix of proteoglycans and glycoproteins. This layer (glycocalyx) is directly bound to the plasma-membrane. ${ }^{36,37}$ An immobile plasma layer consisting of soluble plasma proteins including glycosaminoglycans is attached to this glycocalyx. Together, these layers are known as the ESL, with a thickness ranging from $0.5 \mu \mathrm{m}$ to more than 1.0 $\mu \mathrm{m} .{ }^{36}$ The presence of the ESL may influence several physiological functions of the vessels including flow resistance, barrier function, leukocyte adhesion, coagulation, and angiogenesis. ${ }^{36}$ Damage to the ESL seems to be the earliest detectable injury to the vascular wall in atherosclerosis. ${ }^{37}$ Free radicals, as produced by oxidized low-density lipoproteins or activated leukocytes, can disrupt this surface. ${ }^{37}$ It could be that the increase in intraluminal diameter we observed with increasing severity of atherosclerosis or inflammation partly reflects a diminishing ESL.

That higher leukocyte count, lower HDL levels, higher body mass index, higher waist-to-hip ratio and smoking were related to a lower AVR supports the suggestion that the AVR is also a marker of inflammation and endothelial dysfunction. ${ }^{16}$

\section{Conclusions}

Our data confirmed that elevated blood pressures were associated with smaller arteriolar diameters, but revealed that larger venular diameters were related to atherosclerosis, inflammation, and cholesterol levels. Hence, the idea that the AVR overall reflects generalized arteriolar narrowing should be reevaluated by taking into account the separate arteriolar and venular diameters. These data indicate that the venular diameters do not remain constant in different pathologic conditions and may play their own independent role in predicting cardiovascular disease. In future research, more attention should be paid to the role of venules in vascular disease.

\section{Acknowledgments}

The authors thank the general practitioners and pharmacists in Ommoord, The Netherlands, for their contribution to the Rotterdam Study.

\section{References}

1. Dodson PM, Lip GY, Eames SM, Gibson JM, Beevers DG. Hypertensive retinopathy: a review of existing classification systems and a suggestion for a simplified grading system. J Hum Hypertens. 1996;10:93-98.

2. Walsh JB. Hypertensive retinopathy. description, classification, and prognosis. Ophthalmology. 1982;89:1127-1131.

3. Ikram MK, Borger PH, Assink JJ, Jonas JB, Hofman A, de Jong PT. Comparing ophthalmoscopy, slide viewing, and semiautomated systems in optic disc morphometry. Opbthalmology. 2002;109: 486- 493 . 
4. Parr JC, Spears GF. Mathematic relationships between the width of a retinal artery and the widths of its branches. Am J Ophthalmol. 1974;77:478- 483 .

5. Parr JC, Spears GF. General caliber of the retinal arteries expressed as the equivalent width of the central retinal artery. Am J Ophthalmol. 1974;77:472-477.

6. Hubbard LD, Brothers RJ, King WN, et al. Methods for evaluation of retinal microvascular abnormalities associated with hypertension/sclerosis in the Atherosclerosis Risk in Communities Study. Ophthalmology. 1999;106:2269-2280.

7. Wong TY, Klein R, Klein BE, Tielsch JM, Hubbard L, Nieto FJ Retinal microvascular abnormalities and their relationship with hypertension, cardiovascular disease, and mortality. Surv Ophthalmol. 2001;46:59-80.

8. Wong TY, Klein R, Couper DJ, et al. Retinal microvascular abnormalities and incident stroke: the Atherosclerosis Risk in Communities Study. Lancet. 2001;358:1134-1140.

9. Wong TY, Klein R, Sharrett AR, et al. Retinal arteriolar narrowing and risk of diabetes mellitus in middle-aged persons. JAMA. 2002; 287:2528-2533.

10. Wong TY, Klein R, Sharrett AR, et al. Retinal arteriolar narrowing and risk of coronary heart disease in men and women. The Atherosclerosis Risk in Communities Study. JAMA. 2002;287:11531159.

11. Sharrett AR, Hubbard LD, Cooper LS, et al. Retinal arteriolar diameters and elevated blood pressure: the Atherosclerosis Risk in Communities Study. Am J Epidemiol. 1999;150:263-270.

12. Wong TY, Hubbard LD, Klein R, et al. Retinal microvascular abnormalities and blood pressure in older people: the Cardiovascular Health Study. Br J Ophthalmol. 2002;86:1007-1013.

13. Leung H, Wang JJ, Rochtchina E, et al. Relationships between age, blood pressure, and retinal vessel diameters in an older population. Invest Ophthalmol Vis Sci. 2003;44:2900-2904.

14. Wong TY, Klein R, Sharrett AR, et al. Cerebral white matter lesions, retinopathy, and incident clinical stroke. JAMA. 2002;288: 67-74.

15. Wong TY, Klein R, Sharrett AR, et al. The prevalence and risk factors of retinal microvascular abnormalities in older persons: The Cardiovascular Health Study. Ophthalmology. 2003;110:658-666.

16. Klein R, Sharrett AR, Klein BE, et al. Are retinal arteriolar abnormalities related to atherosclerosis? - The Atherosclerosis Risk in Communities Study. Arterioscler Thromb Vasc Biol. 2000;20: $1644-1650$

17. Hofman A, Grobbee DE, de Jong PT, van den Ouweland FA. Determinants of disease and disability in the elderly: the Rotterdam Elderly Study. Eur J Epidemiol. 1991;7:403-422.

18. Wolfs RC, Borger PH, Ramrattan RS, et al. Changing views on open-angle glaucoma: definitions and prevalences-The Rotterdam Study. Invest Ophthalmol Vis Sci. 2000;41:3309-3321.

19. Van Leeuwen R, Klaver CC, Vingerling JR, Hofman A, De Jong PT. The risk and natural course of age-related maculopathy: follow-up at 61/2 years in the Rotterdam Study. Arch Ophthalmol. 2003;121: 519-526.
20. Knudtson MD, Lee KE, Hubbard LD, Wong TY, Klein R, Klein BE. Revised formulas for summarizing retinal vessel diameters. Curr Eye Res. 2003;27:143-149.

21. Littmann $H$. Determining the true size of an object on the fundus of the living eye (in German). Klin Monatsbl Augenbeilkd. 1988; 192:66-67.

22. Meijer WT, Hoes AW, Rutgers D, Bots ML, Hofman A, Grobbee DE. Peripheral arterial disease in the elderly: The Rotterdam Study. Arterioscler Thromb Vasc Biol. 1998;18:185-192.

23. Bots ML, Hofman A, De Jong PT, Grobbee DE. Common carotid intima-media thickness as an indicator of atherosclerosis at other sites of the carotid artery. The Rotterdam Study. Ann Epidemiol. 1996;6:147-153.

24. Witteman JC, Kok FJ, van Saase JL, Valkenburg HA. Aortic calcification as a predictor of cardiovascular mortality. Lancet. 1986;2: $1120-1122$.

25. van Gent CM, van der Voort HA, de Bruyn AM, Klein F. Cholesterol determinations: a comparative study of methods with special reference to enzymatic procedures. Clin Chim Acta. 1977;75:243251.

26. Vliegenthart R, Geleijnse JM, Hofman A, et al. Alcohol consumption and risk of peripheral arterial disease: the Rotterdam study. Am J Epidemiol. 2002;155:332-338.

27. Knudtson MD, Klein BE, Klein R, et al. Variation associated with measurement of retinal vessel diameters at different points in the pulse cycle. Br J Ophthalmol. 2004;88:57-61.

28. Tso MO, Jampol LM. Pathophysiology of hypertensive retinopathy. Ophthalmology. 1982;89:1132-1145.

29. Wang JJ, Mitchell P, Leung H, Rochtchina E, Wong TY, Klein R. Hypertensive retinal vessel wall signs in a general older population: the Blue Mountains Eye Study. Hypertension. 2003; 42:534-541.

30. Leishman $\mathrm{R}$. The eye in general vascular disease: hypertension and arteriosclerosis. Br J Ophthalmol. 1957;41:641-701.

31. Wong TY, Klein R, Klein BE, Meuer SM, Hubbard LD. Retinal vessel diameters and their associations with age and blood pressure. Invest Ophthalmol Vis Sci. 2003;44:4644-4650.

32. Su TC, Jeng JS, Chien KL, Sung FC, Hsu HC, Lee YT. Hypertension status is the major determinant of carotid atherosclerosis: a community-based study in Taiwan. Stroke. 2001;32:2265-2271.

33. Klein R, Sharrett AR, Klein BE, et al. The association of atherosclerosis, vascular risk factors, and retinopathy in adults with diabetes: the atherosclerosis risk in communities study. Ophthalmology. 2002;109:1225-1234.

34. Williamson TH. Central retinal vein occlusion: what's the story? Br J Ophthalmol. 1997;81:698-704.

35. Prandoni $\mathrm{P}$, Bilora F, Marchiori A, et al. An association between atherosclerosis and venous thrombosis. $N$ Engl J Med. 2003;348: 1435-1441.

36. Pries AR, Secomb TW, Gaehtgens P. The endothelial surface layer. Pflugers Arch. 2000;440:653-666.

37. Vink H, Constantinescu AA, Spaan JA. Oxidized lipoproteins degrade the endothelial surface layer: implications for platelet-endothelial cell adhesion. Circulation. 2000;101:1500-1502. 